\title{
DIALÉTICA E RETÓRICA EM PEDRO ABELARDO
}

João Carlos Salles Pires da SILVA ${ }^{1}$

- RESUMO: Abelardo é reconhecido como um argumentador temível. Neste texto, procuramos mostrar como o uso de expedientes retóricos e o refinamento de sua técnica argumentativa associam-se intimamente e encontram em sua obra uma justificação teórica. Assim, recursos (como a redução ao absurdo), que parecem apenas garantir o sucesso e sobrevivência do mestre itinerante, apontam para a defesa filosófica da independência da linguagem; deste modo, ao tempo em que denunciam a extrema inserção do filósofo em seu contexto histórico e sua preocupação com seu específico público, condensam elementos de sua autonomia intelectual e pioneirismo.

- PALAVRAS-CHAVE: Abelardo; dialética; retórica; redução ao absurdo; autoridade.

Misto de poeta e lógico, de soldado e filósofo, personagem romanesca e mestre intinerante, "reunião rara de aventura e de sabedoria", ${ }^{2}$ Pedro Abelardo figura na história da filosofia como argumentador temível, guerreiro dialético, protagonista da urbanização da vida acadêmica e predecessor de um gênero filosófico que faria fortuna nos séculos seguintes, a questão disputada. E decerto a imagem do filósofo beligerante não é gratuita ou infundada. Abelardo lançava-se nas discussões como em um duelo em que tudo se permite. Tal a sua maestria, seus inimigos todos, mesmo os justamente célebres, temiam sua palavra. Assim, por exemplo, dirigindo-se confiante ao Concílio de Sens, onde suas posições confrontar-se-iam às dos cistercienses, Abelardo, em nada humilde, contava poder dobrar seus adversários, favorecer-se pela palavra da atenção da assembléia; entretanto, em lá chegando, descobriu-se na condição de réu, em virtude da poderosa ingerência de São Bernardo, cuja refinada prosa mística só se equiparava à parcela de poder então enfeixada em suas mãos:

1 Departamento de Filosofia - Universidade Federal da Bahia - 40171-970 - Salvador - BA. Doutorando em Filosofia - Unicamp - 13081-970 - Campinas - SP.

2 Expressão de Jolivet (s.d., p.3). 
Em que pesem as razões teológicas e políticas de São Bernardo para opor-se a Abelardo, após violentos ataques prévios, o concílio foi levado a adotar uma forma completamente espúria: ao invés de aceitar a disputa entre duas concepções, um dos contendores foi de antemão transformado em réu. Os adversários de Abelardo sempre se viram obrigados a prestar-lhe esta homenagem: nenhum deles jamais dispôs-se a enfrentá-lo em seu próprio terreno. (Estevão, 1990, p.40)

Fazendo-lhe justiça, importa observar que São Bernardo tentara enfrentar Abelardo com as armas da dialética, pois em princípio nada tinha contra os filósofos antigos ou contra a razão; além disso, leitor de Agostinho, aprendera bem que, "para voltar a suas origens celestes, a alma deve recorrer também às artes liberais": "foi somente quando percebeu que as armas de seu adversário superavam as suas que se esquivou, como os lutadores dos torneios, protegendo-se como eles e pondo-se ao abrigo após um primeiro choque, para recorrer enfim a outros meios, menos nobres, menos humildes" (Duby, 1990, p.133, 132).

Em meio à narrativa de suas calamidades, encarregou-se Abelardo de propagar sua fama de virtuose nas artes do trivium, mas esta é também com suficiência (ao exagero, inclusive) atestada por vários contemporâneos, como a traçar por seu perfil um destino. Notável, neste sentido, ainda que descontemos a natureza do texto, é o epitáfio de Abelardo, composto por Pedro, o Venerável:

O Sócrates de França, o Platão sublime do Ocidente, nosso Aristóteles, o igual ou o mestre de todos os lógicos passados e presentes, o príncipe reconhecido da ciência em todo o universo, gênio variado, sutil, penetrante, vencedor de todos os obstáculos pela força da razão e a graça de sua palavra: tal era Abelardo. ${ }^{3}$

Seduzido pelas letras, Abelardo renuncia aos direitos de primogênito e à herança para abraçá-las, mas a opção pelo "regaço de Minerva" guarda um evidente sentido militar, não implica renúncia a um ideário e a um vocabulário da classe dominante; pelo contrário, o espírito próprio à "corte de Marte" parece mesmo indispensável a um novo mister, é mais que uma idiossincrasia. Assim, quando carrega de tons beligerantes seu lugar de filósofo, Abelardo abraça uma ética profissional, funda-a talvez: "Eu preferi as armas dos argumentos dialéticos a todos os ensinamentos da filosofia, troquei as outras armas por essas e antepus os choques das discussões aos troféus das guerras" (1984, p.254). Le Goff comenta a opção de Abelardo com pompa e circunstância; busca sem dúvida recuperar, pintando-o talvez em tons demasiado fortes, o sentido inovador, a ousadia desse filho da pequena nobreza do Pallet:

A escolha é necessária e dramática. Novo Esaú que sacrifica a pompa militaris gloniae ao studium litterarum, Abelardo tem de renunciar, ao mesmo tempo, ao seu direito de primogenitura. Assim, a escolha do que irá tornar-se uma profissão fá-lo sair radicalmente do seu grupo social, é renúncia a um gênero de vida, a uma mentalidade, a um ideal, a uma estrutura familiar e social. Em vez disso, um compromisso total: Tu enis magister in aeternum. (1980, p.171)

3 Citado em Guizot, s.d., p.361. 
Como texto que flagra e explicita elementos de uma consciência de grupo, de sua base econômica, de sua moral profissional e mesmo da sua vindicação retórica, o relato de Abelardo de suas calamidades é um notável documento histórico-literário. Podemos destacar dois pontos: em primeiro lugar, Abelardo mostra a urgência e o desconforto do ensino que breve seria o universitário e o urbano, por oposição ao monástico: ser filósofo é "proceder pela inteligência e não pela rotina"; é perturbar autoridades bem estabelecidas, sendo exemplares dessa sensibilidade os vários episódios, quer de conflito com monges rudes, quer de disputa intelectual com antigos mestres, sendo natural o conseqüente entusiasmo despertado entre os estudantes quando passa "a discorrer sobre o próprio fundamento da nossa fé por meio de analogias propostas pela razão humana" (1984, p.272). ${ }^{4}$ Por seu ensino, "inaugurava-se uma teologia fundada principalmente sobre a dialética. Abelardo partia da palavra. Mas não, como nos mosteiros, deixando-se levar ao devaneio, às associações fortuitas de vocábulos ou de imagens. E sim pelos rigores do raciocínio" (Duby, 1984, p.113). Em segundo lugar, a rejeição do trabalho manual, a afirmação desse meio único de ganhar a vida, a saber, o "servir-se da própria língua", arrebanhando alunos, fugindo e atacando, tomando de assalto, destruindo ou fundando escolas. ${ }^{5}$ Le Goff, em certo momento de um comentário seu, não se contém: "Mesmo tomando as necessárias precauções, sem atribuir ao vocabulário do século XII um significado e um alcance anacrónicos, há que reconhecer aqui a inovação, a ousadia, o longo alcance" (1980, p.173).

\section{2}

Testemunho biográfico e reflexão teórica se completam. Abelardo narra sua aventura peripatética e descobrimos nela um raro exemplo de identidade entre vida e teoria. O ter-se tornado o "êmulo dos peripatéticos", "perambulando pelas diversas províncias a travar debates" (1984, p.254), afigura-se-lhe como um método de instru-

4 "Eles me pediam argumentos humanos e filosóficos, e insistiam mais naqueles que pudessem ser entendidos do que proferidos, dizendo ser supérflua a prolação de palavras sem a compreensão das mesmas, e que não se pode crer naquilo que antes não se entendeu, e que é ridículo alguém pregar aos outros o que nem ele próprio nem aqueles que ensina podem compreender com o intelecto" (Ibidem, p.272). Talvez não seja ocioso lembrar que tal exigência, relativa aqui à dificílima (nunca plenamente acessivel) questão teológica da unidade e da trindade de Deus, aplica-se, a fortion, à querela dos universais.

5 Um pequeno detalhe aqui deve ser levado em conta. Os problemas lógicos relativos à enunciação começavam na evidência da fala - e isto não só para Abelardo como para muitos contemporâneos. Os enunciados têm sua verdade discutida não desprezando o fato de serem elocuções, o que explica a importância, por vezes conduzida ao anedótico, da contribuição de Roscelino. Alguns paradoxos parecem decorrer, por exemplo, desse truísmo: Um argumento compõe-se de orações. Ora, uma vez que seu dictum significa o verdadeiro ou o falso, a oratio, precário processo temporal, é o veículo do raciocínio. A primeira dificuldade reside em que, palavras ao vento, friç̧ão da boca, apenas quando extinta uma elocução pode ser significativa - paradoxo solucionável apenas se produz uma inteleç̧ão, um objeto mental, um pensamento. Outro problema a recordar-nos a presença falante de Abelardo: os nomes não apagam sua imposição original, dependendo seu emprego regular de um contexto de acordos lingüísticos, onde passam a engendrar "mais intelecção do que opinião, porque o seu descobridor teve a intenção de impô-los de acordo com algumas naturezas ou propriedades das coisas, ainda que nem ele próprio soubesse excogitar convenientemente a natureza ou a propriedade da coisa" (Abelardo, 1994, p.67). 
ção, uma necessidade da pesquisa. Afinal, a prova "racional" requer empenho, adestramento. Por isso, não podemos definir a racionalidade por nossa limitação, afastando como exótico o que nos surpreende ou escapa a nossos hábitos de reflexão. Caso contrário, corremos o risco de agir como os que "chamam de estultície tudo aquilo que não entendem, e de loucura o que são incapazes de compreender" (1982, p.316). Não nos deve faltar o devido adestramento, que só se dá na pesquisa, ou seja, não basta orar nem implorar, "devemos pesquisar, disputando uns com os outros" (p.317). Treino-disputa tanto mais urgente se desejamos rebater as investidas de hereges e infiéis, pois só assim conseguiremos, contra sua "loquacidade" e "as armadilhas de suas afirmações", "refutar suas argumentações e invalidar seus sofismas com argumentos verdadeiros, para que o erro ceda à verdade e os sofismas recuem perante os dialéticos" (Ibidem). O verdadeiro dialético estará assim tanto mais próximo de Cristo, "que é a própria verdade", quanto mais forte se mostrar "na verdade das argumentações" (Ibidem).

Sabemos que esse modo de produção da autoridade pela dialética em tudo e por tudo devia irritar quantos afirmassem, por exemplo, com São Bernardo, que "a fé dos fiéis crê, não discute" (Duby, 1990, p.159) - posição metodicamente distante da procura contínua, da interrogação freqüente que, em Sic et Non, Abelardo afirma ser a primeira chave da sabedoria. Se a disputa é o meio de adestramento, vence-a inequivocamente quem é capaz de mostrar enredado o adversário nos nós de sua própria trama. Deste modo, a redução ao absurdo é uma técnica argumentativa a ser privilegiada, porquanto por meio dela se retiram as conseqüências lógicas contraditórias de hipóteses que assim se evidenciam falsas. ${ }^{6}$ A redução ao absurdo parece comportar, mais que qualquer outra técnica, a dimensão característica da utilização guerreira da dialética, seu exercício reproduz o movimento pelo qual roubamos a espada do adversário, instrumento por si neutro, mas do qual o herético abusa. A redução ao absurdo atende ainda, primorosamente, à necessidade de persuasão, parecendo unir em grau máximo a sutileza da técnica dialética e a eficácia destrutiva da retórica, pois "ninguém pode ser refutado senão a partir do que concede, nem convencido senão pelo que admite" (1969b, p.139).

Por si só a dialética é louvável, "espada bem amolada semelhante àquela de que se serve o tirano para destruir e o príncipe para proteger" (1978, p.50). Grave e

6 A redução é expediente corriqueiro em Abelardo. Por exemplo, para provar a equivalência entre as "conseqüências" (i) Si est homo est animal [ ( Hx Ü $\sim$ Ax)] e (ii) Si non est animal non est homo [ $\sim \sim \mathrm{Ax} \dot{\mathrm{U}} \sim(\sim \mathrm{Hx}))$ ], admite a hipótese de alguém duvidar de (ii) e aceitar (i) - hipótese que se mostra, pela ilustrativa formalização, mais que absurda, impossivel, porquanto estrita e formalmente equivalentes as "conseqüências". Ora, "se alguém admite a primeira das consequentiae citadas acima e duvida da segunda o que está a fazer é aceitar que de facto pode não haver nenhum animal embora haja um homem. Mas pela primeira consequentia, que ele aceita, tem que haver um animal se há um homem. E assim a pessoa que objecta é forçada a dizer que podia não haver nenhum animal embora houvesse um animal", o que é logicamente impossivel (Kneale \& Kneale, 1980, p.224-5). Vale, porém, observar a distinção entre reductio ad absurdum e reductio ad impossibile, pois naquela "as conclusões derivadas das hipóteses não têm que ser auto-contraditórias mas podem por vezes ser simplesmente falsas" (Ibidem, p.11). 
questionável é portanto a intenção - conceito central na ética de Abelardo. 7 "Ciência da discussão", a importância da dialética é enorme, inclusive no estabelecimento do sentido do texto sagrado - "necessário é apenas guardar-se da paixão da disputa e desta glória pueril que nos leva a enganar o adversário" (p.50). Mas este é apenas um sinal do abuso, a ilusão sofística, ciência do mal sem que possa ser má qualquer ciência, "pois o que é mal não é saber iludir ou fornicar: é sim cometer tais atos; é bom conhecer o que todavia é terrível de se fazer; não se peca por conhecer o pecado, mas ao cometê-lo" (p.51). A dialética fornece as armas, neutras, necessárias, quando o simples argumento de autoridade, seja dos santos seja dos filósofos, revela-se insuficiente. Ela, a dialética, pode então oferecer-nos, para combater os loucos segundo sua loucura, para nos opormos com raciocínios aos que só se deixam afetar por raciocínios, "algo que seja verossímil, próximo da razão humana sem ser contrário à Escritura Sagrada". ${ }^{8}$

O enfraquecimento da autoridade e a sedução fácil dos sofistas, acredita Abelardo, devem-se em muito ao fato de que "quase todos os homens são psíquicos e poucos são espirituais", ou seja, devem ser atingidos por raciocínios e meios humanos e apenas deles se saciam. Mais um motivo, portanto, e de ordem retórica, para um adestramento na dialética. Parece ser necessário, embora paradoxal, reforçar a autoridade, socorrê-la mesmo, pois (como diz o Cristão no Diálogo) não pode ser considerado razoável admitir o duvidoso sem ao menos uma razão, porquanto, em suma, "expor a verdade de uma razão tem mais força que produzir uma autoridade" (1969b, p.139) - isto, caso estejamos em uma discussão, sendo ademais correlativa a o caráter dos participantes a força própria à autoridade ou à razão e, em conseqüência, a tática a ser usada. A autoridade depende da circunstância, da admissão de um método. Contra o filósofo, pouco vale, afirma o Cristão, "sendo necessário usar outra tática" (p.139).

Abelardo, bom tático, sempre soube conformar seu discurso a seu público, em jogo de influências bastante rico. Sua vida e obra parecem documentar o tipo de comércio entre o popular e o erudito, entre o acadêmico e o mundano, que tanto interessa ao historiador das mentalidades. Quem era o público de Abelardo? O mesmo,

7 "Abelardo atribui valor moral apenas à intenção (intentio) com que são realizados os atos humanos, sejam eles bons ou maus" (Estevão, 1990, p.83). Uma definição tornada assim central depende de uma vontade que possa assentir (ou não) ao mal; logo, depende de um bem definido indivíduo que possa, por seu consentimento (ou não) ao que é proibido por Deus, conferir sentido a seus atos. Tal posição exige "o privilégio da consciência, da interioridade" (Ibidem, p.84). O conceito de "intenção", que singulariza a ética de Abelardo, deve encontrar confirmação e contrapartida em um movimento geral de sua obra; e, de fato, Abelardo opõe-se em todos os campos de sua reflexão a tudo quanto possa impedir a distinção entre os indivíduos, postulando sempre sua radical irredutibilidade. Por conseguinte, também sua reflexão ética exige um confronto lógico-ontológico com o realismo de um Guilherme de Champeaux, pois, "se entendermos que os homens se encontram na mesma essência (o homem), não teriamos como distinguir substancialmente a cada um" (Ibidem, p.180).

8 Abelardo, 1978, p.56: "Mais ni l'autorité des saints ni celle des philosophes ne peut réfuter des arguments importuns, à moins qu'on ne s'oppose avec des raisonnements humains à ceux qui se laissent emporter par des raisonnements humains: c'est pourquoi nous avons décidé de répondre aux fous suivant leur folie et de briser leurs assauts en usant des arts mêmes au moyen desquels ils nous assaillent". 
certamente, que se deliciava com jogos de palavras ou neologismos como o "rudibilis" de Abelardo (próprio do homem é rir, e não zurrar; o homem é risibilis, e não rudibilis) - público a ser seduzido e também sedutor, pois público de Paris, cidade-antro segundo os cistercienses: "Oh! Paris, como és capaz de encantar e decepcionar as almas! Em ti as seduções dos vícios, as armadilhas dos males, as flechas do Inferno, fazem perder os corações inocentes..." (Celles apud Le Goff, 1973, p.28).

Abelardo (pelo menos o inventado por Le Goff) fala, primeiro, para semelhantes, para os que, como ele e como os goliardos, "escolheram o estudo em detrimento da guerra":

No nobre ele [o goliardo] detesta também o militar, o soldado. Para o intelectual urbano, os combates do espírito, os torneios da dialética substituíram dignamente os feitos de armas e as proezas guerreiras. O Arquipoeta de Colônia transmitiu-nos a sua repulsa pela carreira das armas (me terruit labor militaris), assim como Abelardo, que foi um dos maiores poetas goliardos [sic!], em obras que se recitavam e cantavam no Monte Sainte-Geneviève, tal como se trauteiam as cançōes da moda, e que infelizmente se perderam. (Le Goff, 1973, p.41)

Segundo, Abelardo fala para muitos, pois todos os registros o indicam famoso e concorrido. Assim, deve ter tido em seu público representantes suficientes da vagabundagem intelectual que tanto caracterizou o século XII: "Estes estudantes pobres não têm nenhum domicílio fixo, nenhuma renda eclesiástica, nenhum benefício, seguem desse modo a sua aventura intelectual, acompanhando o mestre que mais lhes agradou, acorrendo em direção àquele de que mais se fala..." (Ibidem, p.33). Abelardo, ele próprio, deixa transpirar indícios acerca do ânimo de seu público, que decerto nada tinha de uniforme, embora devesse encontrar nestes traços salientes uma de suas coordenadas.

A posição de Abelardo sobre as "autoridades" é, no mínimo, ambígua. Que devam ser veneradas, é óbvio! Mas só podem ser tomadas sem restrições quando há plena convergência - sinal talvez de que o consenso humano se fez entre os melhores. Trata-se, assim, de um argumento verossímil, "racional" mesmo, sem que Abelardo chegue a enunciá-lo como necessário, como o faz em certo momento a personagem do discípulo em $O$ gramático de Santo Anselmo. ${ }^{9}$ Argumento da tradição, o apelo à autoridade é de bom alvitre, confiável porquanto resultante de um "consenso de tes-

9 "Que o gramático, porém, seja uma qualidade, confessam-no abertamente os filósofos que trataram desse assunto, e seria um atrevimento contestar-lhes a autoridade a respeito dessas matérias" (Anselmo, 1984, p.173). A afirmação do consenso sustenta o argumento, podendo torná-lo sólido, mas não deixa de ser estranho encontrá-lo como necessário ao lado de uma derivação silogística. 
temunhas que, ao longo dos séculos, depõem unanimemente". ${ }^{10}$ Autoridades assim dificilmente podem ter o nariz torcido, enquanto é bastante contestável e de todo falacioso o puro e simples recurso a uma autoridade qualquer: "Aqui, na maior parte dos casos, alega-se um autor, cita-se um texto, fora do tempo e do espaço e sem preocupação pelo processo de esclarecimento do assunto". ${ }^{11}$

O Sic et Non opera em um campo em que o desejado consenso não pode ser estabelecido sem uma operação da razão, estando carente de socorro sua solidez. Tratava de arbitrar concordância entre textos discordantes, mas uma tal arbitragem, um tratamento criterioso das autoridades, trabalho por vezes de filólogo ou de detetive, era já uma inovação, em uma época e em um ofício em que a inovação raramente era considerada meritória. Percebemo-nos, portanto, em terreno minado, se consideramos mover-se Abelardo no interior de uma religião revelada, em que a leitura da página e a palavra da autoridade apresentam-se como métodos os mais naturais. A produção e reprodução "rotineira" da leitura autorizada da página sacra é método descartado por Abelardo, que entretanto jamais perde a oportunidade de servir-se de alguma citação pertinente e de fuçar a letra ou o espírito das autoridades, de pôr seu nariz no lugar, ou às vezes de empiná-lo levemente. Mutatis mutandis, é o que ainda fazemos ao trabalhar nossas fontes, ao inventar uma tradição, ao produzir nossas autoridades. Não obstante, ao estabelecer critérios de razão para decidir sobre a Verdade, e em meio às divergências dos santos, Abelardo transtorna a hierarquia, subordina-a a uma leitura, propõe-nos, como o melhor, o mais lúcido, o mais persuasivo, um método preferencial, verossímil, de aproximação a verdades nunca plenamente acessíveis, quando relativas a questões teológicas, cuja verdade só o Senhor sabe: "Tudo que exporemos a propósito de tão elevada filosofia, afirmamos que é uma sombra, não a verdade; uma espécie de analogia, não a coisa mesma" (1978, p.56).

Fé e razão enfrentam uma delicada negociação em Sic et Non. Nesta obra, em que mais se sutiliza a defesa da dialética, porquanto instrumentada em razão de autoridade presumida, Abelardo apresenta expedientes de leitura com que procura salvar a integridade do sentido dos textos das autoridades. É verdade que Abelardo, em Sic et Non, estava a referir-se aos possiveis obstáculos na interpretação da palavra dos santos, reconduzindo à fraqueza do leitor o que só em aparência pode comportar contradição ou erro, quer seja, a palavra dos que "julgarão as nações". Neste caso, além de muitos cuidados filológicos relativos, entre outros, à seleção do texto, sepa-

10 Chenu apudLe Goff, 1984, p.89. Além disso, como o afirmou João de Salisbury, "ainda que o sentido das palavras modernas seja o mesmo que o das antigas, a antigüidade merece maior veneração" (Boehner \& Gilson, 1982, p.333).

11 Chenu apud Le Goff, 1984, p.89. Questionamo-nos se não estamos incorrendo em erro semelhante ao nos apoiarmos tanto, por exemplo, em Le Goff, quando suas posições, embora favoreçam ou provoquem nossa leitura de Abelardo, não são consensuais nem pacíficas. Esperamos que um tal questionamento seja considerado um cuidado metodológico ante um possível dilema, que, entretanto, na falta de fontes suficientes, não cremos passível de solução. Por conta disso, devemos confessar, nosso recurso à autoridade é e será retórico, mostra provavelmente nada sabermos a respeito. Em todo caso, é melhor dizer com a autoridade até o que não sabemos. 
rando materiais apócrifos ou corrompidos por copistas, Abelardo mostra ter bem consciência de duas importantes interferências na correta interpretação de um texto, uma de ordem lógica, outra retórica. Assim, por um lado, "o mais freqüente encontrar-se-á uma solução fácil às contradições, caso se possa sustentar que as mesmas palavras foram empregadas em sentidos diferentes por diferentes autores"; neste sentido, se tornarmos essa sua observação em cuidado na exegese de sua própria obra, termos tão familiares como "abstração" e "estado de coisa" devem ser reaprendidos, sobretudo por nos aproximarmos de uma época que luta por fixar um vocabulánio filosófico elementar. Por outro lado, Abelardo ressalta com extremo vigor a importância da intenção predicante dos autores, condicionada por conseguinte "pela diversidade desses a quem nos dirigimos" (1969a, p.141, 140). ${ }^{12}$ Destarte, o próprio Abelardo alerta: todo cuidado é pouco no restabelecer do sentido de um texto. Caso não seja possível, por nenhum meio dialético, harmonizar declarações divergentes; caso nossa fraqueza não tenha encontrado os meios para dirimir um conflito de opiniões, Abelardo adiciona, como recurso extremo de supressão da dúvida, um último expediente: quando o conflito entre as autoridades persistir, devemos optar pela melhor autoridade. Uma vez que "é certo que a graça da profecia por vezes faltou aos próprios profetas", devemos pois escolher aquela autoridade "cujo testemunho é o mais forte e a garantia a melhor" (p.141).13

\section{4}

A defesa da dialética por Abelardo funda, inclusive, o recurso à autoridade - o que, paradoxalmente, denunciaria falha no próprio recurso ou impotência. Sendo recorrente, é mais do que sintomática, evidenciando-se na defesa muitos elementos de sua singular retórica. Todos sabemos que essa defesa constante coincide com a emergência de uma personagem e de uma forma de exercício intelectual doravante clássicas, a saber, o mestre e a questão disputada; por isso, mais importante foi recusar o mero registro histórico e assinalar como tais razões (tanto de defesa da dialética como de combate aos pseudodialéticos) são interiores à obra. Caso contrário, estaríamos apenas apresentando como novidade o que já sabíamos sem a necessidade de qualquer pesquisa. Como resultado geral dessa defesa, podemos anotar: a melhor autoridade é sempre uma autoridade construída, que conta com algo mais que um mero assentimento. Mais do que isso, é justificada, resulta de considerandos, e estes, porque considerandos, tornam mesmo a mais irrestrita obediência em novidade filosófica. Se temos em conta apenas este passeio caleidoscópico pelas suas várias defesas da dialética, não podemos reprovar Cousin por seu entusiasmo, embora o julguemos suspeito e excessivo:

12 A pergunta, decisiva a nosso texto, pela composição do público a quem se dirige, comporta, portanto, um cuidado manifesto do próprio Abelardo.

13 Temos em seu critério de recurso à mais forte autoridade um cuidado bastante atual para historiadores da filosofia, se o traduzimos no ato exegético de conferir uma atenção primeira à sua palavra. 
Através de alguns séculos de distância, Abelardo e Descartes filiam-se nacionalmente; por isso se nota entre eles, apesar de todas as diferenças, uma semelhança assombrosa ... Ambos duvidam e investigam, querendo compreender o mais possível, e tão-só descansam na evidência: tal é o traço fundamental que recebem do espírito francês. ${ }^{14}$

SILVA, J. C. S. P. da. Dialectics and rhetoric in Peter Abelard. Trans/Form/Ação (São Paulo), v.19, p.221-230, 1996.

- ABSTRACT: Abelard is acknowledged as a dreaded arguer. In this paper we try to demonstrate how the refinement of his argumentative technique associate intimately and find a theoretical justification in his work. Thus, the resources (like the reduction to the absurd) that seem just to guarantee the success and survival of the itinerant master point to the philosophical defense of the independence of language; therefore, those resources not only denounce the philosopher's extreme insertion in his historical context and his concern about his specific public, but they also condense elements of his intellectual autonomy and pioneering spirit.

- KEYWORDS: Abelard; dialectics; rhetoric, reduction to the absurd; authority.

\section{Referências bibliográficas}

ABELARDO, P. Prologue du Sic et Non. In: JOLIVET, J. (Org.) Abélard ou la philosophie dans le langage. Paris: Seghers, 1969a.

Usage de l'argumentation en Matière de Foi (Dialogue). In: JOLIVET, J. Abélard ou la philosophie dans le langage. Paris: Seghers, 1969b.

Du Bien Suprême. Introd. e Notas de J. Jolivet. Paris: Vrin; Montréal: Bellarmin, 1978.

Defesa da dialética. In: BOEHNER, P., GILSON, E. História da filosofia cristã. Petrópolis: Vozes, 1982.

A história das minhas calamidades. In: ANSELMO (Santo), ABELARDO, P. Monólogo; Proslógio; A verdade; O gramático; Lógica para principiantes; A histónia das minhas calamidades. São Paulo: Abril Cultural, 1984. p.251-82. (Col. Os Pensadores).

Lógica para principiantes. Intr. e Trad. de C. A. R. do Nascimento. Petrópolis: Vozes, 1994.

14 Citado em Guizot, s.d., p.389. Decerto, deveriamos aqui ir ao detalhe, mostrar como a fúria dialética de Abelardo, aqui vindicada, se singulariza e tece em sua obra uma ligação essencial entre expedientes retóricos e correção formal. Isto é o que fazemos no texto "Sócrates e Burnello" (que, pela limitação de espaço, separamos para publicação em outro lugar). Em tal texto, procuramos analisar os pressupostos ontológicos, a correção formal e o contexto de um dos argumentos esgrimidos por Abelardo contra o realismo de Guilherme de Champeaux, a saber, o argumento que mostra ser consequiência do realismo a absurda negação da oposição dos contrários, com o que estaria obrigado o realista a conceder a proposição "Sócrates é Burnello". 
ANSELMO (Santo). O gramático. In: ANSELMO (Santo), ABELARDO, P. Monólogo; Proslógio; A verdade; O gramático; Lógica para principiantes; A histónia das minhas calamidades. São Paulo: Abril Cultural, 1984. p.171-197. (Col. Os Pensadores).

BOEHNER, P., GILSON, E. História da filosofia cristã. Petrópolis: Vozes, 1982.

DUBY, G. São Bernardo e a arte cisterciense. São Paulo: Martins Fontes, 1990. L'Europe au Moyen Âge: art roman, art gothique. Paris: Flammarion, 1984.

ESTEVÃO, J. C. O indivíduo na ética de Abelardo. São Paulo, 1990. 267p. Dissertação (Mestrado em Filosofia) - Pontifícia Universidade Católica, 1990.

GUIZOT, F. G. Abelardo y Eloisa. Madrid: La España Moderna, s.d.

JOLIVET, J. Abelardo entre cão e lobo. Trad. de C. A. R. do Nascimento. s.d. 32p. (Mimeogr.). (Original publicado in Cahiers de Civilisation Médiévale, v.20, n.4, 1977).

KNEALE, W., KNEALE, M. O desenvolvimento da lógica. Lisboa: Fundação Calouste Gulbenkian, 1980.

LE GOFF, J. Os intelectuais na Idade Média. Lisboa: Estúdios Cor, 1973.

. Para um novo conceito de Idade Média: tempo, trabalho e cultura no Ocidente. Lisboa: Estampa, 1980. A civilização do Ocidente medieval. Lisboa: Estampa, 1984. v.II. 